being developed to allow measurements to be made while polymers degrade in the instrument under controlled conditions.

The pottant must be protected from solar UV by an absorbing material on the sunside surface. Glass could be used but it is heavy and fragile. A polymer film would be highly suitable but must be very resistant to degradation. Very few clear polymer films will remain tough for long in bright sunlight. Of a great range tested by Boeing in concentrated Arizona sunshine (and for hail resistance with an intriguing iceball throwing machine!) only two fluorocarbons - polyvinyl fluoride and polyvinylidene fluoride (trade names Tedlar and Kynar) - stood up to 10 (accelerated) years without embrittlement or discolouration. Various other points must be kept in mind. The fluorocarbons are not cheap materials and polyvinylfluoride also has the drawback that it is very difficult to process. The stability of the fluorocarbons is thought to be due to the strength of the carbon-fluorine bond but little work has been done on oxidation of these materials and it is not clear how this protects the normally vulnerable $\mathrm{C}-\mathrm{H}$ bonds in the molecule. Dust tends to stick to the surfaces of polymer films and reduce the transmitted light intensity. Fluorocarbon films, however, seem to be self-cleaning, probably because a surface film forms and washes off with the dust when it rains.

Films are also needed as covers for heated water solar collectors and, when metallized, have been used as 'inflatable' mirrors. There is thus a real requirement for a cheap, transparent photostable film. A group at Brookhaven National Laboratory has designed a solar collector for roof mounting which is made from all thin film materials stretched on a steel frame and estimates that it can thus achieve a tenfold reduction in weight and a fivefold reduction in cost.

As well as passive uses, the symposium provided examples of polymers in the active role, replacing the silicon in photovoltaic cells. Preliminary studies were reported on polymeric phthalocyanines from Xerox of Canada, on heattreated polyacrylonitrile and on polyacetylene. These materials offer the potential of cheap photocells using powders or thin films as opposed to expensive silicon single crystals. Amorphous silicon already represents a move in this direction. However, these relatively disordered systems are characterized by a high density of defects so that few of the freed electrons manage to travel from the point where light is absorbed to the electrode. Thus pure single crystal silicon reaches efficiencies above ten per cent, amorphous silicon is cheaper to produce but reaches an efficiency of two to three per cent while the organic films are only producing fractions of one per cent in efficiency. Hence the prospect of solar power from polymer painted on the roof of a house is a long way off.

\title{
Tree rings and archaeology: dating Roman oaks
}

\section{from J.M. Fletcher}

THE recent discovery of the wooden foundations for a Roman bridge across the Rhine at Koblenz has provided an exciting opportunity for European dendrochronology to prove its worth to archaeology. The dating of the bridge was one of the topics discussed at the recent workshop organized by the European Science Foundation which brought dendrochronologists and archaeologists together at the Wood Biology Institute of the University of Hamburg.

The site of the bridge had been identified when waterway engineers, searching in a large bell for underwater objects which might be a danger to shipping, found stumps protruding from the silt. They appeared to be remains from $600-700$ piles which had supported pillars that carried the bridge. For each pillar the Romans had inserted into the river bed, on a regular grid, 25 oak piles estimated to have been 10-15 $\mathrm{m}$ long. They were the trunks, about $50 \mathrm{~cm}$ wide, of slow-grown trees about 250 years old when felled. From the widths of the rings on stumps extracted from the river bed B. Schmidt (University of Cologne) was able to date construction of the bridge accurately to AD 49 - an achievement possible because of the tree ring chronology built up for central Germany and because some of the stumps retained all their sapwood. Schmidt also concluded that to provide the straightness necessary for being driven into the ground, the oaks were $Q$ uercus petraea rather than $Q$. robur, and that the level of the Rhine at the time was about $1.5 \mathrm{~m}$ higher than at present.

Other applications described at the workshop ranged over several millenia and illustrated the magnitude of the research. Oak, as for the Roman bridge, was the wood used in the numerous Neolithic and Bronze Age settlements by the side of Swiss and other lakes formed as a result of the Ice Age around the Alps. Thousands of samples excavated from more easily available sites are enabling U. Ruoff (University of Zurich) and $\mathrm{H}$. Egger (University of Neuchatel) to place the settlements in a chronological pattern.

Further north, B. Becker (University of Hohenheim, Stuttgart) and others in Germany have extracted hundreds of oaks from the gravels which mark the ancient course of rivers, such as the Danube, Rhine and Main. The widths of their annual rings have enabled a long oak chronology going back many millenia to be constructed for central Europe. It almost rivals in length the chronology derived from conifers,

$J . M$. Fletcher is at the Research Laboratory for Archaeology and the History of Art, Oxford University, Keble Road, Oxford OXI $3 Q J$. including bristlecone pine, which grew in the western part of the US. This European work is of great importance to archaeology for it allows the calibration of radiocarbon results. There has been concern that the American chronology, on which calibration has hitherto been based, may not apply to Europe and other areas. In fact the two calibration curves agree closely in spite of being based on different species, growing in different geographical locations and at different altitudes. Furthermore, by confirming the secular oscillations, or 'wiggles', the European work opens the way to their use as indicators of climatic variations in the distant past.

Another application, to the archaeology of classical, Byzantine and medieval times in the Near East, comes to many as a surprise. Few believed that enough timber had survived in that region to make tree-ring dating a viable technique. In fact, $P$. Kuniholm (Cornell University), with the enthusiasm and persistence of an explorer, has established chronologies for conifers from Greek and Turkish samples obtained from tombs below ground, and temples and churches above ground. Even the Parthenon and similar temples have contributed to the project, as a small block of wood, known as an empolion, was inserted at the interface of each cylindrical 'drum' that built up a column. Small though they were, these picces often had more than 100 rings of annual growth. The slowness of the growth of the Near East conifers, like that of those in the arid south-west of the US, is a help to the dendrochronologist: a millenium can be covered by relatively few samples while the growth pattern of such slow-grown trees is distinctive and provides reliable matching. As with oaks in northwestern Europe, the patterns from trees with narrow rings often match even when grown far apart.

There remains, however, scope for replacing obsolete methodology and for improving the quality of oak chronologies in north-west Europe, since D. Eckstein and S. Wrobel (University of Hamburg) reported that success with dating in the North German plain sometimes amounted to only 50-60 per cent for archaeological samples. This may partly reflect the failure to make use of weisejahre, the years in which the change in growth (an increase or decrease in ring-width) is sufficiently consistent among the many samples which form a chronology to act as indicators. These have proved helpful in the more maritime and temperate parts of Europe in matching and thereby dating the fast grown samples of oak, with relatively few annual rings, that form a substantial proportion of building timber. 